\title{
Síndrome aórtico agudo. Reporte de dos casos y revisión de la literatura
}

\section{Acute aortic syndrome. Two-case report and literature review}

\author{
Oscar Enrique Guzmán-Del Giudice', \\ Elio Paul Lucchesi-Vásquez², \\ Hernán Humberto José Aste-Salazar ${ }^{3}$, \\ Miguel Trelles-de Belaúnde ${ }^{4}$
}

Guzmán-Del Giudice O, Lucchesi-Vásquez E, Aste-Salazar H, Trelles-de Belaúnde M. Síndrome aórtico agudo. Reporte de dos casos y revisión de la literatura. Rev Soc Peru Med Interna. 2021;34(I): I5-27. https://doi.org/10.36393/spmi.v34i1.580

\section{RESUMEN}

La presentación clínica del síndrome aórtico agudo (SAA) impone un reto diagnóstico para los médicos emergenciólogos. Su muy variable forma de presentación y pobre especificidad sintomática tornan el diagnóstico muy difícil, siendo la clave para su diagnóstico el alto índice de sospecha clínica. La disección aórtica es la forma más frecuente de síndrome aórtico agudo, seguido del hematoma intramural y la úlcera penetrante aórtica. Los defectos cardiovasculares congénitos, síndromes genéticos, y variantes genéticas no sindrómicas han sido asociadas al desarrollo de síndrome aórtico agudo. El diagnóstico del SAA puede ser realizado utilizando modalidades imagenológicas tales como la Tomografía, Ultrasonografía y Resonancia Magnética.

Dependiendo del segmento aórtico comprometido, el manejo puede ser médico y/o quirúrgico. Se reportan dos casos de SAA atendidos en el Departamento de emergencia de la Clínica Delgado durante el año 2015.

\section{ABSTRACT}

The Acute Aortic Syndrome (ASS) imposes a diagnosis challenge for emergency physicians. Its very variable clinical presentation and poor symptomatic specificity makes it very difficult to diagnose, being the high clinical-suspicion index the clue for attaining it. Aortic dissection is the most common form of AAS, followed by intramural hematoma (IMH) and penetrating aortic ulcer (PAU). Congenital cardiovascular defects, genetic syndromes, and nonsyndromic genetic variants have all been

I Médico adjunto. Departamento de Emergencia. Clínica Delgado, Lima, Perú.

2 Médico emergencista. Departamento de Emergencia. Clínica Delgado, Lima, Perú.

3 Médico cirujano.. Cirugía Torácica y Cardiovascular. Clínica Delgado, Lima, Perú.

4 Médico radiólogo. Departamento de Radiología. Clínica Delgado, Lima, Perú. linked with the development of AAS. The diagnosis of AAS in the clinic can be made using imaging modalities such as CT, echocardiography, and MRI. Medical and/or surgical treatment must be provided depending of the compromised aortic segment. We report two cases of AAS received medical care at the Emergency Department of Clínica Delgado during 2015.

\section{INTRODUCCIÓN}

Uno de los principios más importantes en la práctica de la medicina de emergencia es el alto índice de sospecha y el alto nivel de alerta clínica sobre los pacientes. Las patologías agudas de la aorta son un claro ejemplo del motivo para este modus operandi. Son de presentación poco frecuente, y dependiendo de la región comprometida, podrían tener una alta mortalidad. Se reconoce que los factores a favor de la sobrevida son entre otros, el diagnóstico e intervención precoz. 
El manejo de estos pacientes en los departamentos de emergencia es un gran reto. Requieren de una atención oportuna y de un delicado balance coordinado entre los equipos clínicos y quirúrgicos.

A continuación, presentamos dos casos de síndrome aórtico agudo.

\section{PRESENTACIÓN DE LOS CASOS}

\section{CASO 1}

Paciente mujer, 69 años de edad, natural de Piura (norte del país), procedente de Lima, jubilada, quien ingresó al servicio de emergencia reportando tiempo de enfermedad de aproximadamente cinco días, caracterizado por distensión abdominal, dolor abdominal en la región alta del abdomen que ocasionalmente se irradiaba hacia la región lumbar, cambio en la frecuencia y consistencia de las deposiciones, malestar general y dolor intermitente en la región lumbar. Atribuyó las molestias a la ingestión de alimentos diversos durante una reunión familiar en Piura, seis días antes de su ingreso, y el dolor lumbar a una lumbalgia de larga data. Estuvo con una dieta blanda y bebiendo líquidos, pero en los últimos tres días antes de su ingreso presentó hiporexia y muy poca ingestión de líquidos.

Antecedentes de hipertensión arterial en tratamiento regular con telmisartán $80 \mathrm{mg}$ vía oral q24h e hidroclorotiazida $12,5 \mathrm{mg}$ vía oral q24h.

Examen físico: FC 80, FR 25, PA 180/100mm Hg, T 36,6 ${ }^{\circ} \mathrm{C}, \mathrm{SatO}_{2} 98 \%$.

Regular estado general, regular estado de hidratación, regular estado de nutrición, sobrepeso. Sequedad de piel y mucosas. Palidez leve.

Tórax y Pulmones: Amplexación normal, murmullo vesicular normal, no ruidos asociados.

Cardiovascular: Ruidos cardíacos normales, rítmicos, regulares, $1 \mathrm{R}$ normal, $2 \mathrm{R}$ reforzado, no soplos, no edemas, pulsos simétricos y de buena amplitud.

Abdomen: Blando, depresible, dolor difuso a la palpación, ruidos hidroaéreos normales, no masas, no hepatoesplenomegalia, no signos peritoneales, puntos ureterales y puño percusión lumbar no dolorosos. No soplos. SNC: Despierta, lúcida, orientada en espacio, tiempo y persona, movilizando las extremidades, sin alteraciones en la fuerza ni en la coordinación.

Resto del examen sin alteraciones de importancia.

Fue inicialmente atendida con los siguientes diagnósticos de ingreso 1) urgencia hipertensiva, 2) sospecha clínica de un trastorno digestivo a descartar enteritis bacteriana con deshidratación moderada, 3) diagnóstico diferencial de colecistitis aguda, 4) lumbalgia mecano-postural. Se le inició hidratación intravenosa con $\mathrm{NaCl} 0,9 \%$, se administró labetalol 20mg IV en bolo.

Los exámenes auxiliares mostraron $\mathrm{Hb}$ 11,7 g/dl, leucocitos10 760/u; glucosa $113 \mathrm{mg} / \mathrm{dl}$, creatinina 1,66 $\mathrm{mg} / \mathrm{dl}$, urea $80 \mathrm{mg} / \mathrm{dl}$; PCR 3,08 mg/dl; y, el resto de la bioquímica sanguínea dentro de límites normales.

El reporte ultrasonográfico alertó la posibilidad de una disección de aorta abdominal, recomendando realizar angioTEM contrastado para confirmar diagnóstico. (imágenes 1-3)

Se inició infusión de labetalol $2 \mathrm{mg} / \mathrm{min}$, mientras se solicitaba angioTEM y la interconsulta de emergencia a cirugía vascular.

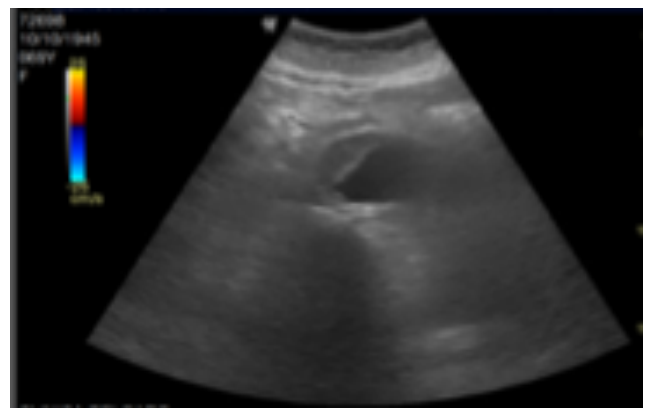

Imagen I

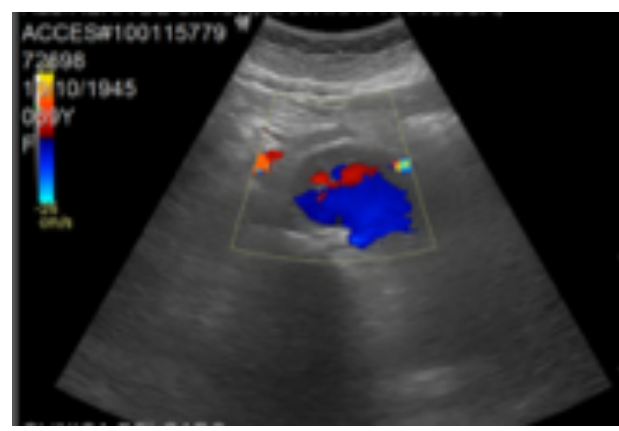

Imagen 2

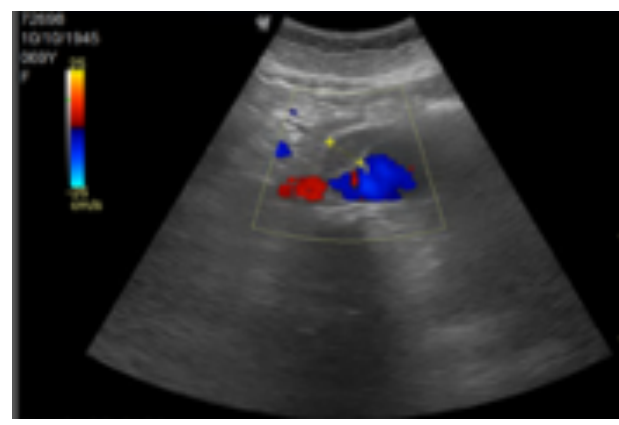

Imagen 3

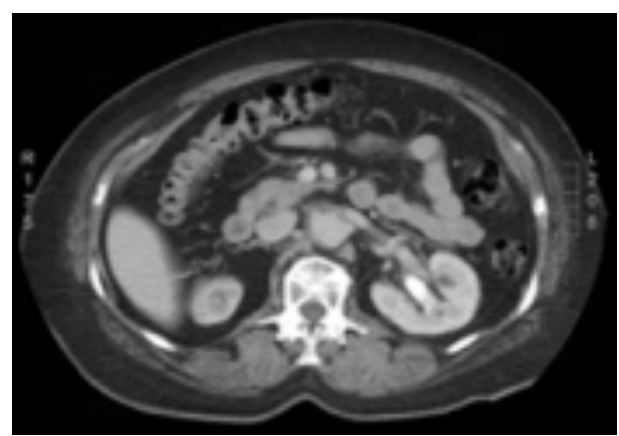

Imagen 4 
La angioTEM (imágenes 4-13) reportó "extenso aneurisma fusiforme de la aorta abdominal desde el origen de la arteria mesentérica superior hasta su bifurcación, con trombos murales irregulares y excéntricos, sin signos de rotura ni de disección al momento del examen. Aneurismas fusiformes a nivel de las arterias iliacas primitivas y de la arteria iliaca derecha".

La paciente fue evaluada por el cirujano vascular de turno, y se decidió pase a la unidad de cuidados intensivos (UCI) para planificación quirúrgica endovascular manteniendo la medicación intravenosa para control de la presión arterial. Se transfirió a la paciente a la UCVI con infusión de labetalol $2 \mathrm{mg} / \mathrm{min}$ durante 48 horas, fue evaluada por nefrología por insuficiencia renal crónica reagudizada y preparada para manejo endovascular. Le colocaron endoprótesis aórtica y, posteriormente, fue dada de alta. En la actualidad en control ambulatorio por nefrología y cardiología.

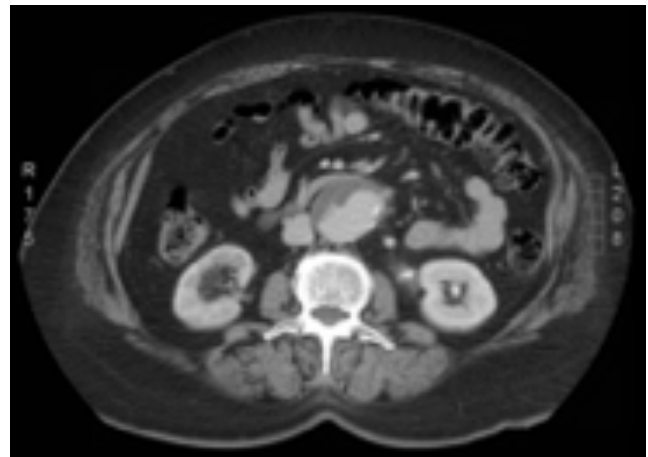

Imagen 5

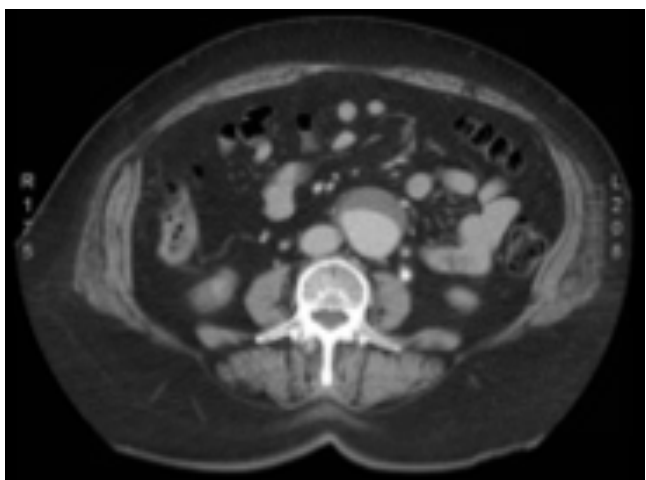

Imagen 6

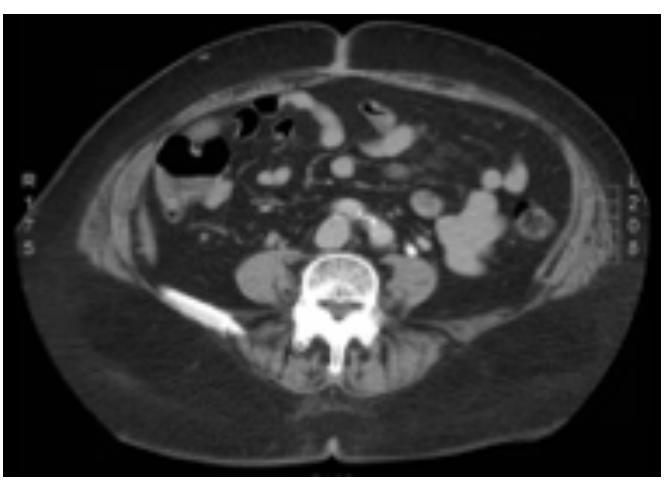

Imagen 7

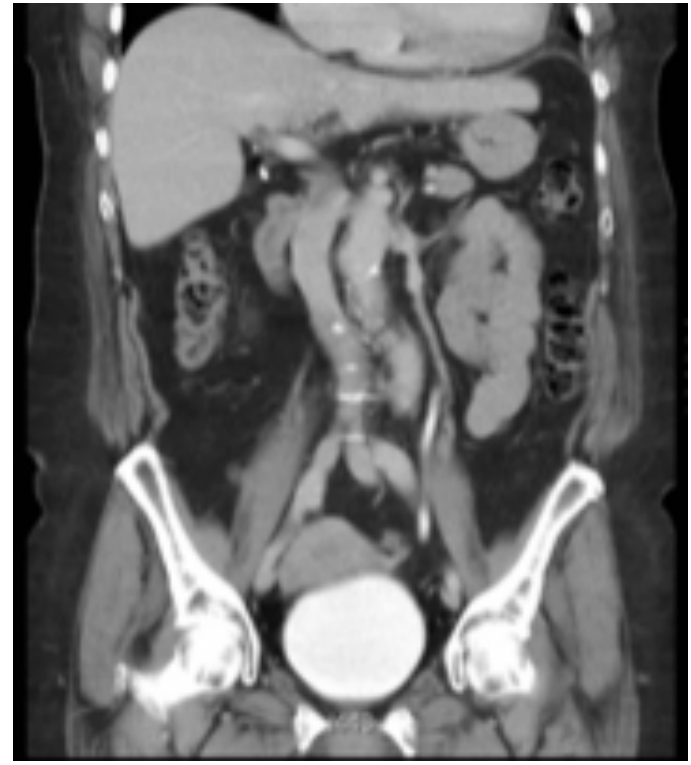

Imagen 8

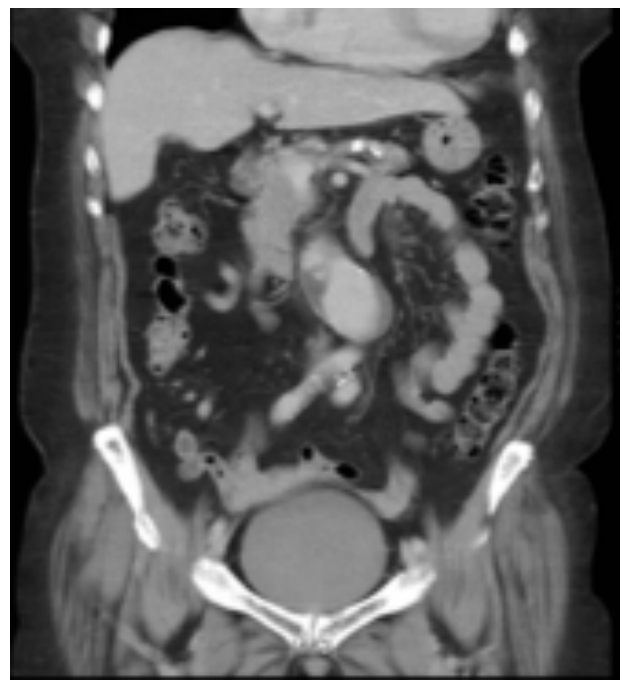

Imagen 9

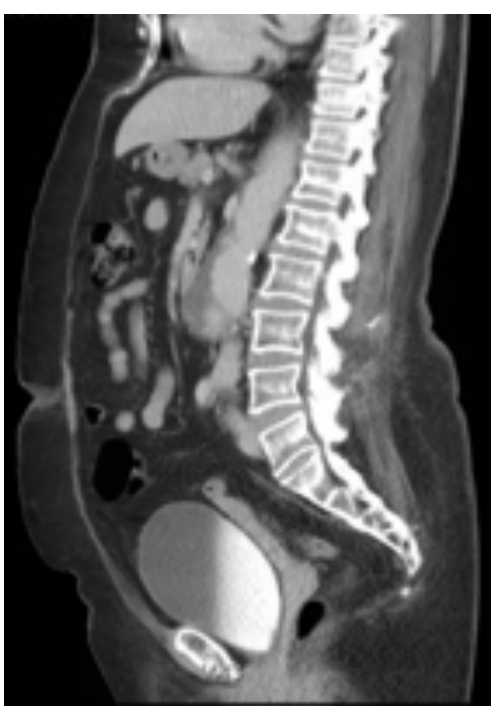

Imagen 10 


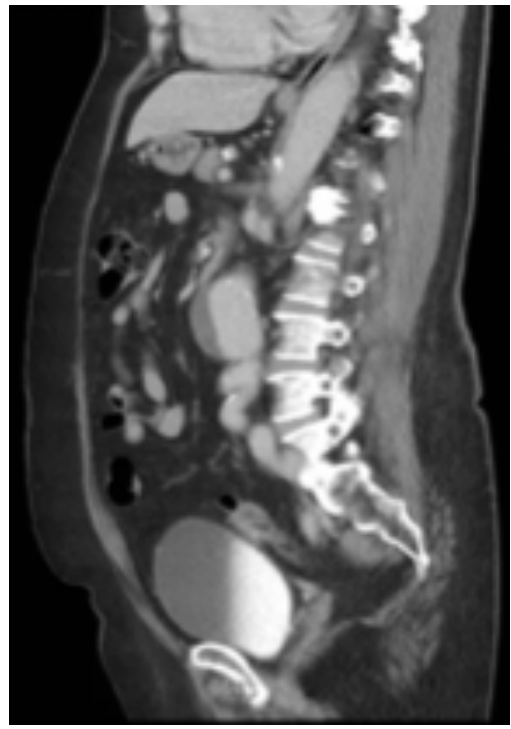

Imagen I I

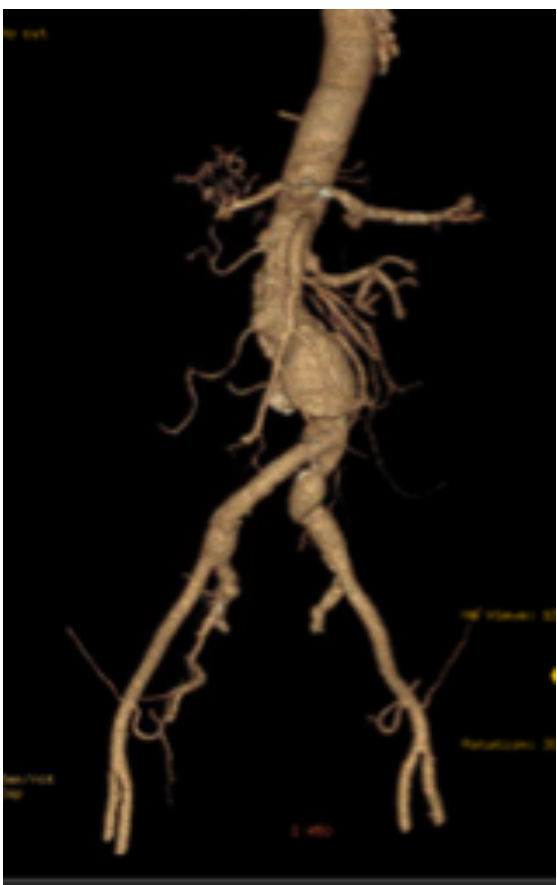

Imagen I 2. Reconstrucción digital. Aneurisma fusiforme de la aorta abdominal.

\section{CASO 2}

Paciente varón, 39 años, natural y procedente de Lima, reportero de televisión, quien acudió al servicio de emergencia refiriendo dolor en la región epigástrica y mesogástrica tipo cólico de inicio súbito, ocasionalmente irradiado hacia la espalda, asociado a náusea y distensión abdominal. Negó otra sintomatología de importancia.

Antecedente de haber sido atendido aproximadamente un mes atrás por dolor torácico atípico irradiado hacia el miembro superior izquierdo, con estudio electrocardiográfico, enzimas cardíacas, ecocardiografía normales y recomendación de control por consultorio externo de cardiología para complementar pruebas, y que no acudió según refirió por falta de tiempo y razones laborales.

Negó otros antecedentes de importancia clínica.

Examen físico: PA 134/78 mm Hg, FC 71 1stidos/min, FR 20 excursiones/min, $\mathrm{T} 36.8{ }^{\circ} \mathrm{C}$, SatO $298 \%$. Buen estado general, buen estado de hidratación, buen estado de nutrición, hábito corporal normal. Piel y mucosas humectadas. No palidez. Tórax y Pulmones: Amplexación normal, murmullo vesicular normal, no rales asociados. Cardiovascular: Ruidos cardíacos normales, rítmicos, regulares, $1 \mathrm{R}$ y $2 \mathrm{R}$ normales, no soplos, no edemas, pulsos simétricos y de buena amplitud. Abdomen: ruidos hidroaéreos normales; blando, depresible, dolor en el epigastrio y mesogastrio, no masas, no hepatoesplenomegalia, Murphy dudoso, no signos peritoneales, puntos ureterales y puño percusión lumbar no dolorosos. No soplos. SNC: Despierto, lúcido, orientado en espacio, tiempo y persona, movilizando las extremidades, sin alteraciones en la fuerza ni en la coordinación.

Resto del examen sin alteraciones de importancia.

Inicialmente fue atendido con los diagnósticos de:1) dolor abdominal, a descartar colecistitis aguda versus pancreatitis aguda.

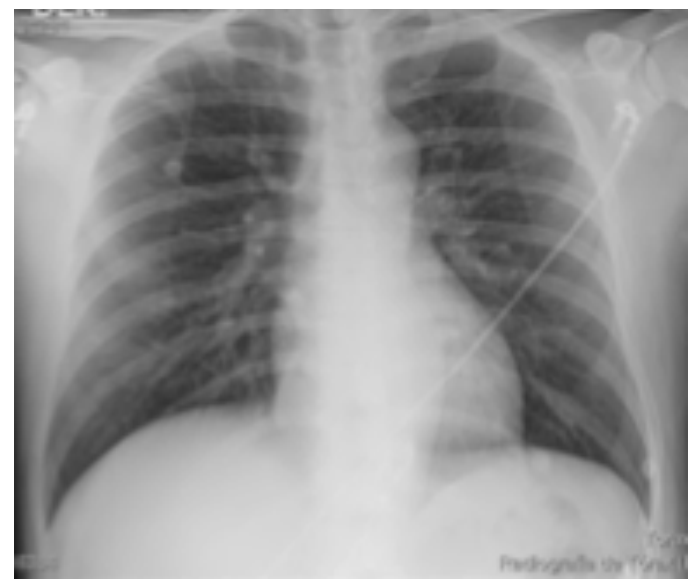

\section{Imagen I 3}

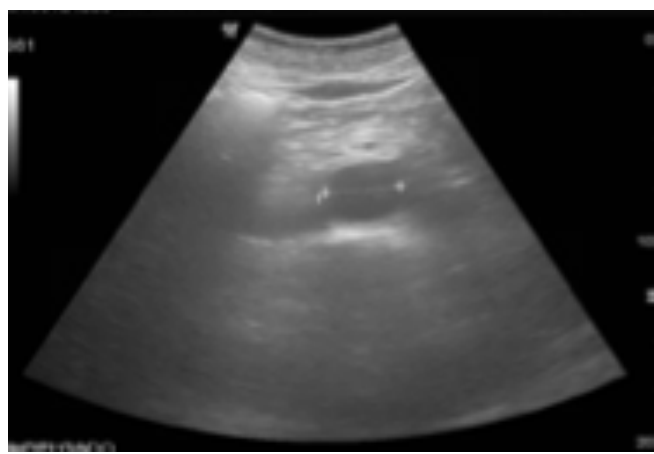

Imagen 14 
Se le solicitó exámenes auxiliares. El hemograma, las pruebas bioquímicas y el examen de orina fueron normales. La radiografía de tórax fue normal (Imagen 13). La ultrasonografía alertó sobre la posibilidad de una disección de aorta abdominal que aparentemente se extiende desde el tórax (Imagen 14).

Se solicitó angioTEM que fue reportada como "1. Aneurisma disecante de la aorta toraco-abdominal (Stanford tipo B), que se extiende al origen del tronco celíaco y compromete el ostium de la arteria renal izquierda. 2. Hematoma en la pared aórtica por encima de la disección que envuelve las arterias dorsales. 3. Aneurisma de la aorta abdominal distal y de las arterias ilíacas primitivas" (Imágenes 15-24).

Se inició infusión con labetalol $1 \mathrm{mg} / \mathrm{min}$, se solicitó interconsulta a cirugía de tórax y cardiovascular.

El paciente fue evaluado por el cirujano vascular de turno, y se decidió pase a la UCI para vigilancia y planificación

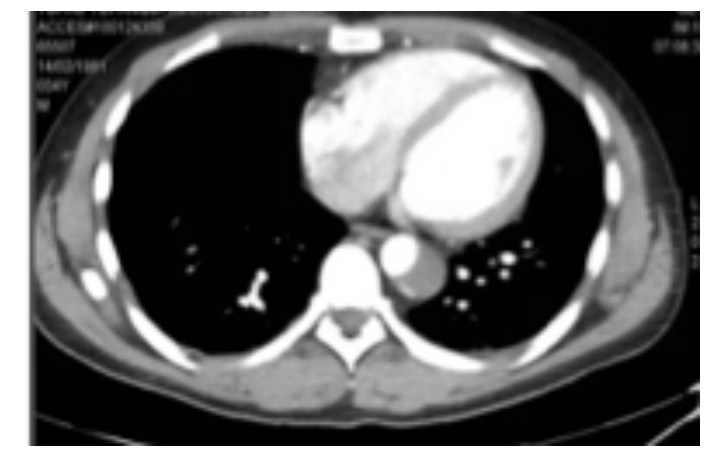

Imagen 15

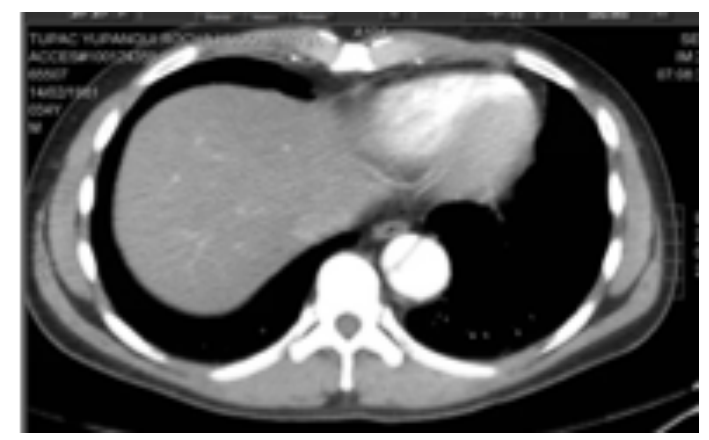

Imagen 16

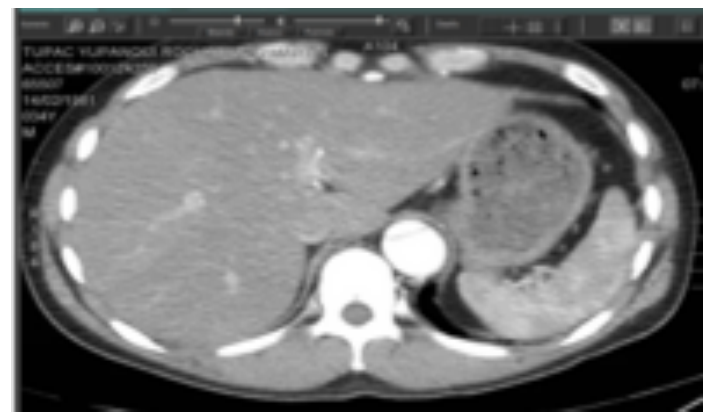

Imagen 17 quirúrgica endovascular manteniendo medicación intravenosa para control de la presión arterial. Se le colocó stent/endoprótesis vascular gastrointestinal + implante de prótesis aórtica + sutura de arteria periférica de extremidad inferior por disección de aorta toraco-abdominal (Imagen 24).

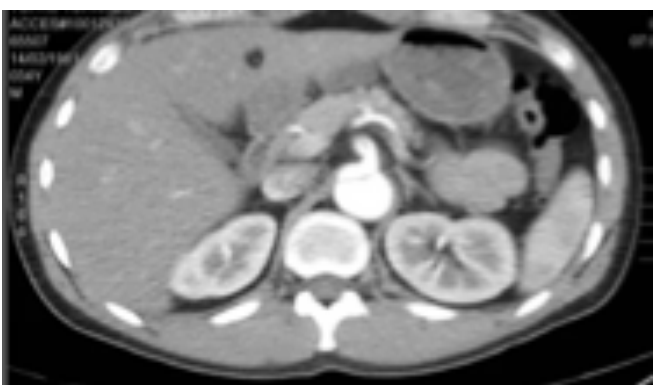

Imagen 18

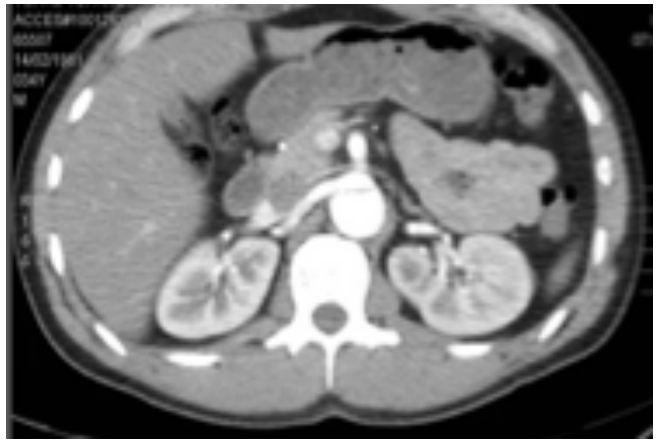

Imagen 19

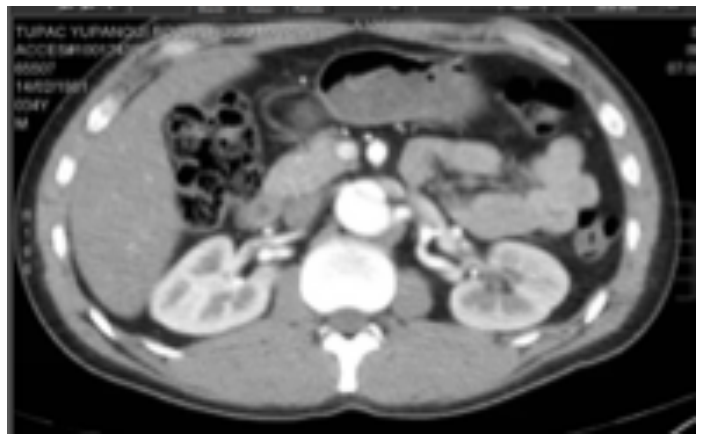

Imagen 20

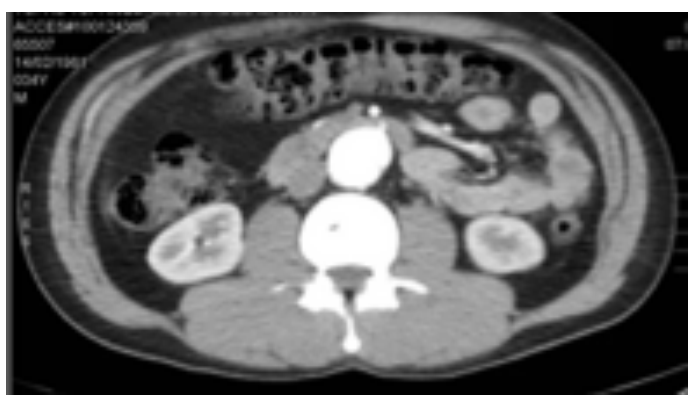

Imagen 2 I 


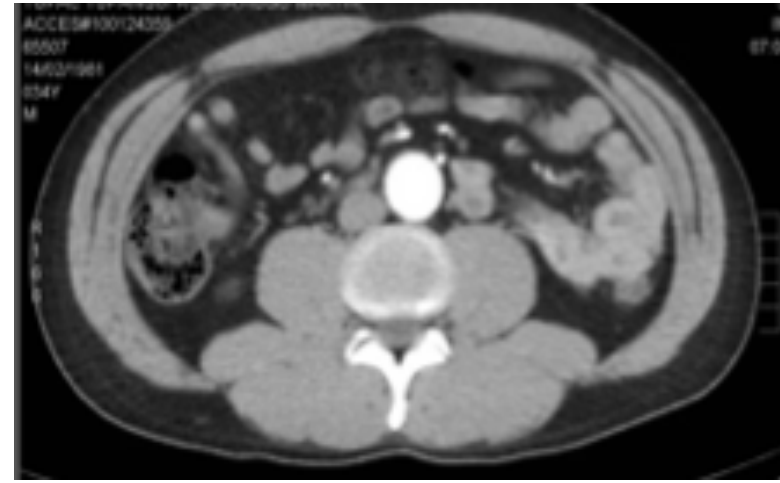

Imagen 22

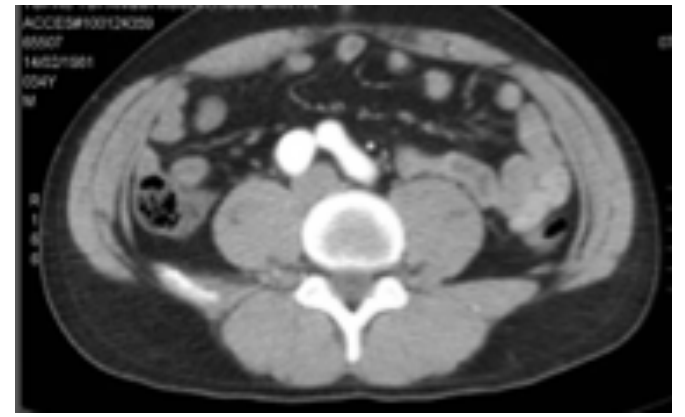

Imagen 23

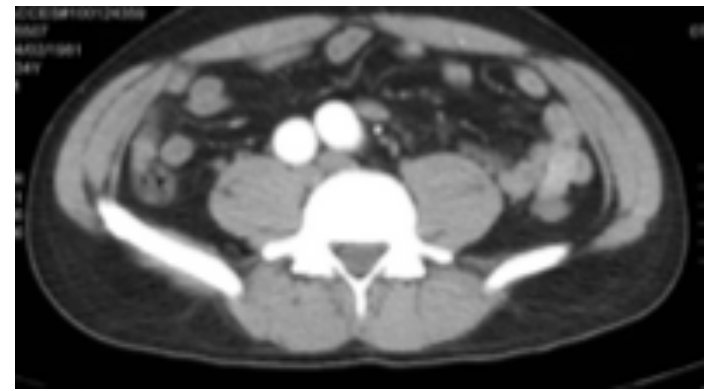

Imagen 24

Hacia el segundo día postoperatorio el paciente presentó agitación psicomotriz, desaturación de $\mathrm{O}_{2}$ arterial. Control de hemoglobina $\mathrm{Hb}$ 6,5g/dl (inicial 12,0 g/dl). No sangrado externo evidente. Se inició transfusión de paquetes globulares y se solicitó angioTEM toracoabdominal por sospecha de hemorragia retroperitoneal. AngioTEM reportado como: "1. Cambios postquirúrgicos relacionados a stent que cubre desde la arteria torácica descendente hasta ambas arterias iliacas comunes. Hematoma retroperitoneal derecho significativo que mide aproximadamente 4,5 x 11,9 x 22,3 cm de diámetro. Pequeño hematoma superficial a la zona de arteriotomía en la ingle derecha. 2. Hiperdensidad en el polo inferior de la corteza renal derecha en relación a fase nefrográfica persistente y probable infarto renal. 3 . Leve estenosis a nivel del origen de la arteria ilíaca común derecha condicionado por la malla. 4. Ligera cantidad de líquido libre en cavidad. 5. Efusión pleural bilateral con atelectasias dependientes asociadas (Imágenes 25-30).

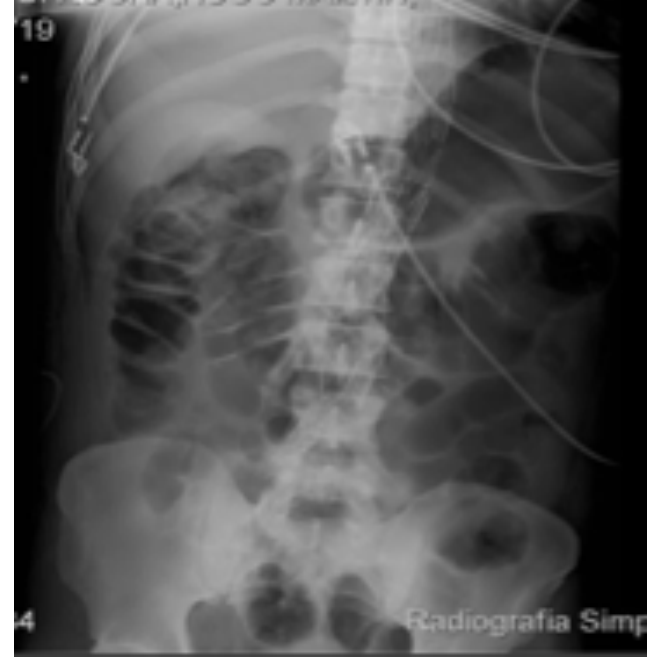

Imagen 25

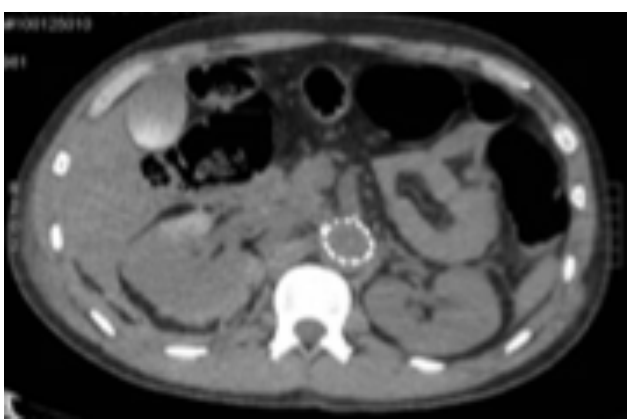

Imagen 26

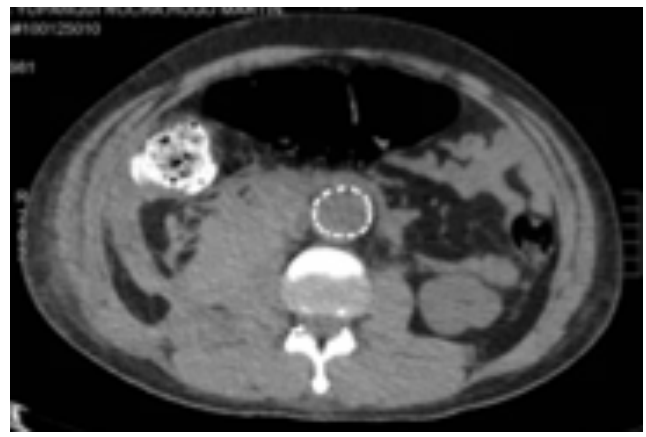

Imagen 27

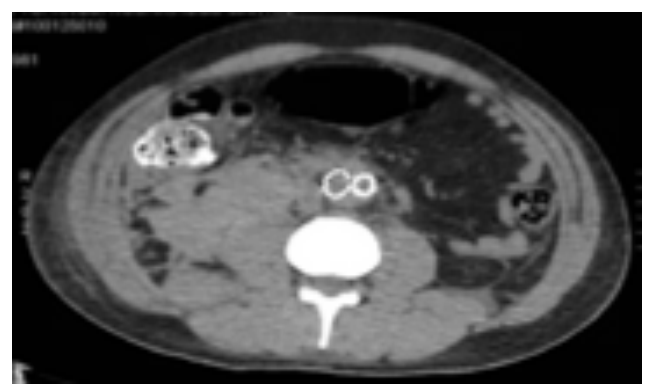

Imagen 28 


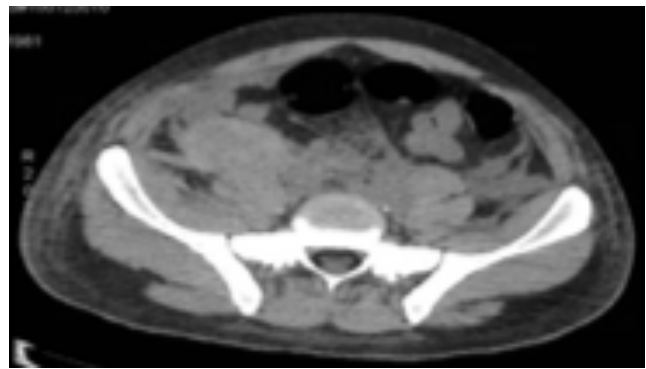

Imagen 29

Se mantuvo en la UCI bajo observación y seguimiento clínico y expectante armada quirúrgica en caso de deterior del paciente. El control horario de la $\mathrm{Hb}$ fue satisfactorio y fue dado de alta de la UCI al sexto día postoperatorio, pasando a sala de hospitalización regular. Se realizó reparación quirúrgica del pseudoaneurisma inguinal derecho encontrado (Imagen 30) y fue dado de alta 16 días después de su ingreso.

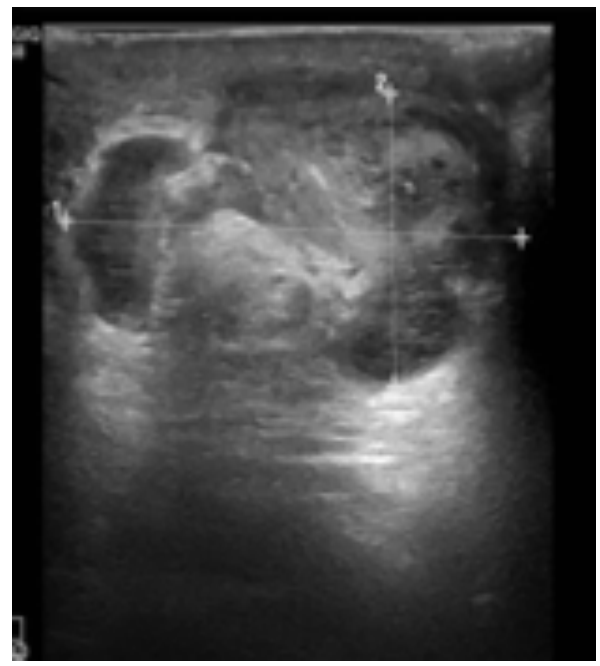

Imagen 30

Acudió a controles ambulatorios por cardiología y cirugía de tórax y cardiovascular, refiriendo mejoría sintomática y presentar evolución favorable.

Reingresó al servicio de emergencia dos semanas después del alta hospitalaria, refiriendo dolor abdominal epigástrico y retroesternal tipo opresivo sin otros síntomas asociados.

Examen físico: PA 136/86 mm $\mathrm{Hg}, \mathrm{FC} 72$ latidos/min, FR 20 excursiones/min, $\mathrm{T} 36,8{ }^{\circ} \mathrm{C}$, $\mathrm{SatO}_{2} 100 \%$. Buen estado general, buen estado de hidratación, buen estado de nutrición, hábito corporal normal. Piel y mucosas humectadas. No palidez.

Tórax y Pulmones: Amplexación normal, murmullo vesicular normal, no rales asociados

Cardiovascular: Ruidos cardíacos normales, rítmicos, regulares, S1 y S2 normales, no soplos, no edemas, pulsos simétricos y de buena amplitud.

Abdomen: ruidos hidroaéreos normales; blando, depresible, dolor en epigastrio y mesogastrio, no masas, no hepatoesplenomegalia, Murphy no doloroso, no signos peritoneales, puntos ureterales y puño percusión lumbar no dolorosos. No soplos. Resto del examen sin alteraciones de importancia. SNC: Despierto, lúcido, orientado en espacio, tiempo y persona, movilizando las extremidades, sin alteraciones en la fuerza ni en la coordinación.

La angioTEM reportó: "1. Pseudoaneurisma en la arteria esplénica a nivel del cuerpo del páncreas, significativamente aumentado de tamaño en comparación con estudio previo.

2. Hematoma retroperitoneal disminuido de tamaño pero mostrando realce periférico de contraste y estriación grasa, hallazgo que aunque no es específico se puede ver con sobre infección. 3. Cambios postquirúrgicos relacionados a malla de stent que cubre desde la arteria torácica descendente hasta ambas arterias ilíacas comunes. A. Endoleak tipo 2 a nivel de la aorta toracica distal, aumentado. B. Endoleak tipo 2 en la aorta abdominal superior e inferior, estable. C. Endoleak tipo 1 a nivel del tercio distal de la malla de stent en la arteria ilíaca común derecha. D. Hematoma mural

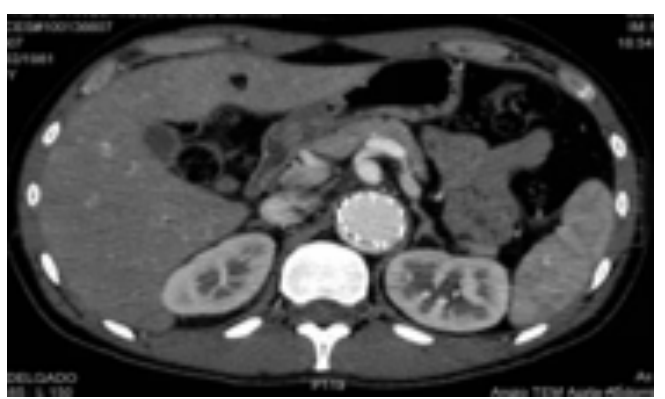

Imagen 3 I

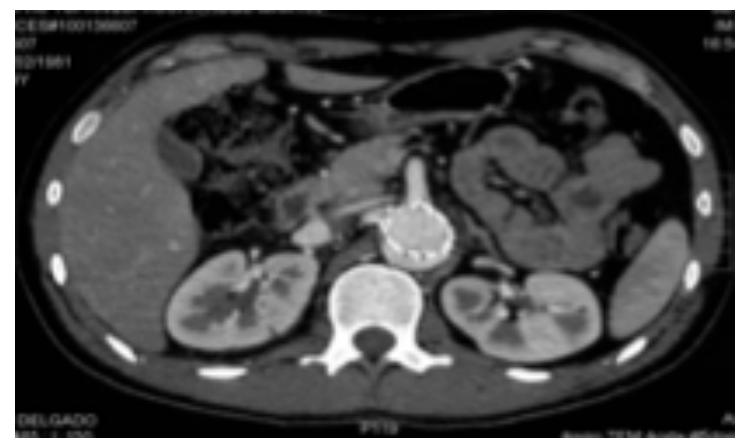

Imagen 32

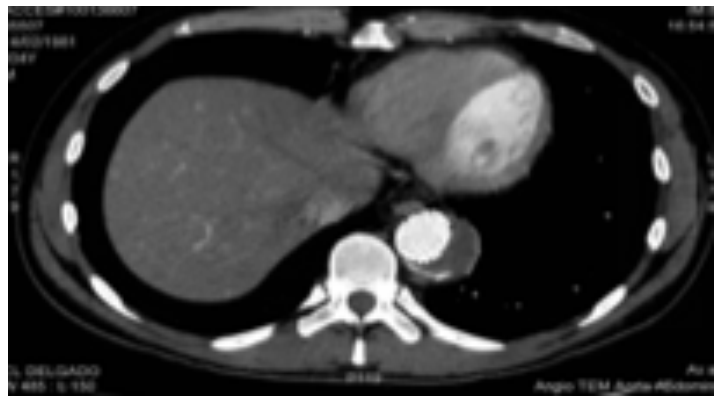

Imagen 33 
a nivel de la arteria torácica distal, estable en tamaño. El resto de los hallazgos, no muestran cambios significativos. (Imágenes 32-33).

El paciente ingresó a UCI para manejo y preparación prequirúrgica para resolver el pseudoaneurisma. Fue trasladado al Instituto Nacional del Corazón para continuar su atención debido a las dificultades económicas del paciente.

\section{DISCUSIÓN}

El síndrome aórtico agudo comprende entidades interrelacionadas, siendo la disección, el hematoma intramural y la ulcera ateroesclerótica penetrante las más frecuentes. A pesar de ser procesos patológicos diferentes, éstos pueden progresar hacia los otros tipos de lesiones. Ver tabla 1 .

Los estudios poblacionales sugieren que la incidencia de la disección aórtica oscila entre 2,6 a 3,5 casos por 100000 persona por año, siendo el sexo masculino el más afectado con dos tercios del total de casos. Se reconocen algunos factores de riesgo asociados a estas entidades, dentro de las cuales la hipertensión arterial, y una variedad de desórdenes genéticos con alteraciones del tejido conectivo que incrementan el riesgo de un síndrome aórtico agudo..$^{1-4}$ Ver tabla 2
Desde el punto de vista fisiopatológico, la sangre se introduce y discurre a través de un desgarro en la pared arterial, separando la capa íntima de la media o adventicia, creando un falso lumen. La propagación de la disección puede proseguir tanto de manera anterógrada como retrógrada desde el punto desgarrado, involucrando ramas laterales del vaso. Esto puede conllevar a complicaciones tales como síndromes de mala perfusión, taponamiento, o insuficiencia valvular aórtica..$^{5-8}$

En la actualidad, se reconoce que tanto las condiciones adquiridas como las genéticas comparten un camino común hacia la pérdida en la integridad de la íntima y su consecuente desgarro. De igual forma, todos los mecanismos subyacentes que producen el debilitamiento de la capa media de la aorta pueden también imponer un alto nivel de estrés y tensión de la pared vascular. Pueden inducir la dilatación de la aorta y formación aneurismática, resultando en una eventual hemorragia intramural, hematoma intramural, disección de aorta o ruptura. (Figura 1)

Las disecciones de aorta pueden ser clasificadas utilizando dos sistemas diferentes: Clasificación de DeBakey y Clasificación Stanford. (Figura 2)

La clasificación más utilizada por su facilidad de uso y mayor correlación para la indicación quirúrgica es la clasificación de Stanford.

\section{Tabla I}

Clase I - Disección clásica de la aorta.

Clase II - Hematoma intramural

Clase III - Disección localizada, desgarro de la íntima sin formación de un flap, formación de un gran flap en la íntima, protrusión o dilatación aneurismática localizada en la pared aórtica.

Clase IV - Úlceras penetrantes de aorta

Clase V - Disección iatrogénica o postraumática.

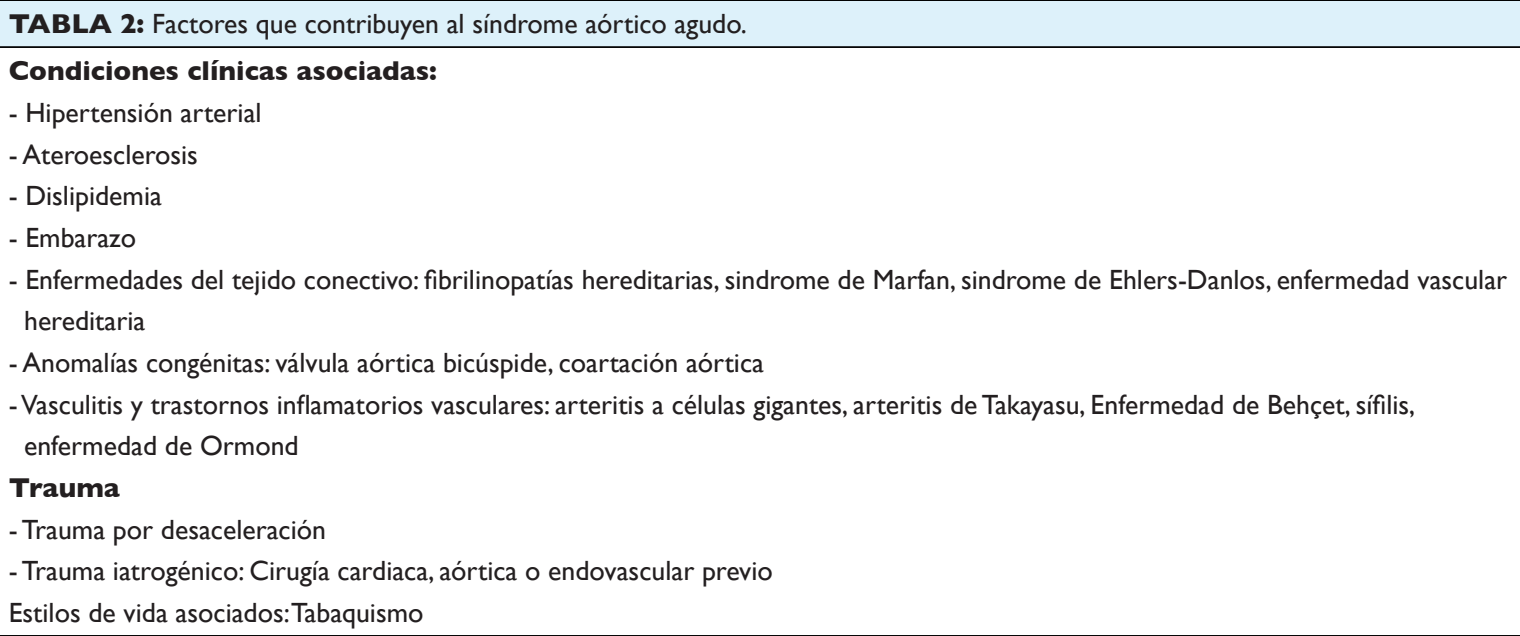


Figura I

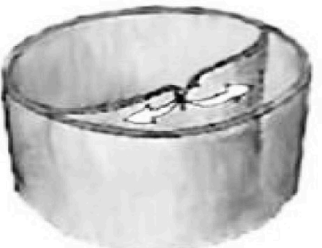

Disección aórtica

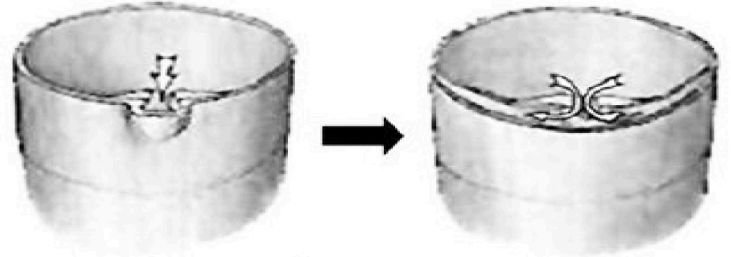

Úlcera penetrante

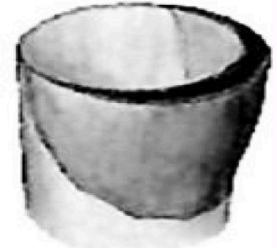

Hematoma intramura

Figura 2

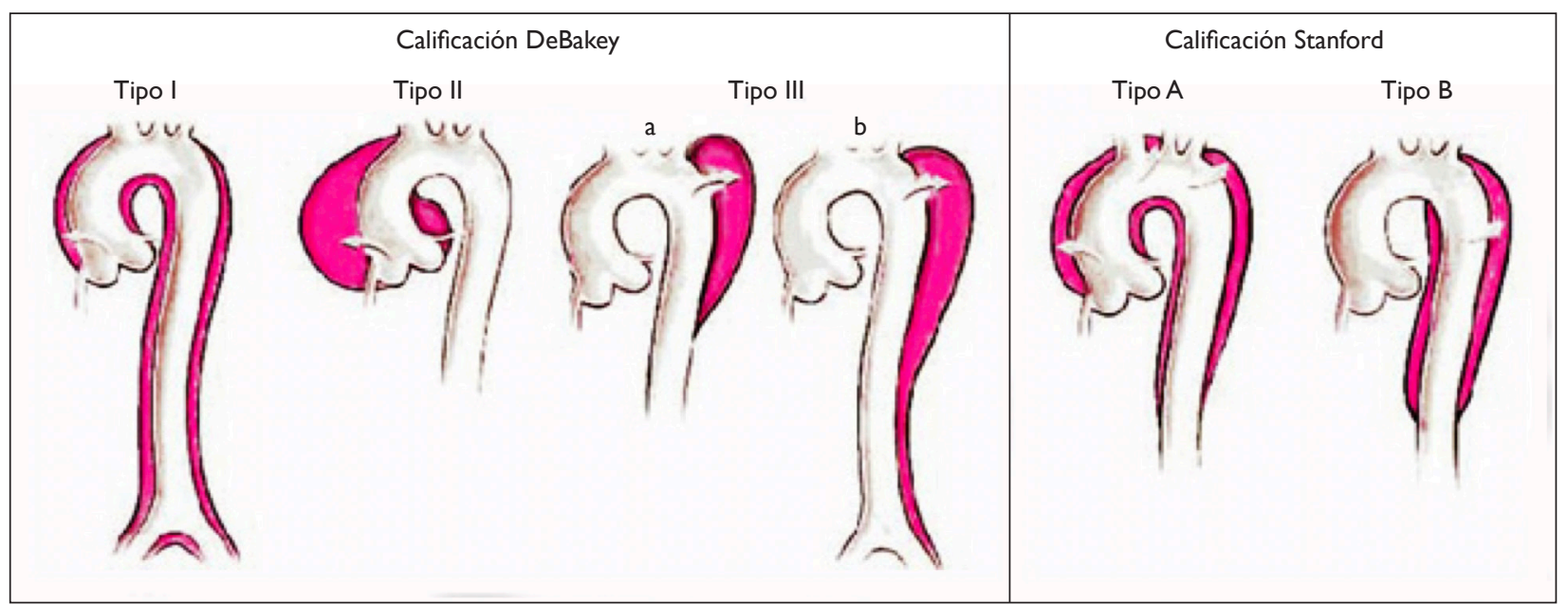

Las disecciones de la aorta descendente (Stanford tipo B o DeBakey tipo III) se dividen en cuatro tipos para efecto del tratamiento endovascular:

- Tipo I. No tiene desgarro íntimo-medial identificable en la aorta torácica descendente.

- Tipo II. Tiene uno o más desgarros íntimo-mediales en la aorta torácica descendente y no hay desgarro a nivel de la arteria celíaca, o distal a ella.

- Tipo III. Tiene desgarro íntimo-medial que implica la aorta abdominal (con o sin desgarros concomitantes en la aorta torácica descendente).
- Tipo IV. Tiene desgarro íntimo-medial distal a la bifurcación aórtica (con o sin desgarros concomitantes en la aorta torácica descendente y abdominal).

La disección de la aorta ascendente (tipo A) es altamente letal, con una mortalidad estimada entre $1 \%$ a $2 \%$ por hora luego del inicio de los síntomas. Sin cirugía, la mortalidad excede el $50 \%$ al mes de iniciado los síntomas; siendo la mortalidad acumulada del $20 \%$ a las 24 horas, $30 \%$ a las 48 horas, $40 \%$ a la semana, y $50 \%$ al mes. ${ }^{9}$ Incluso con tratamiento quirúrgico, la mortalidad es tan alta como 10\% a las 24 horas y $20 \%$ al mes. ${ }^{10,11}$
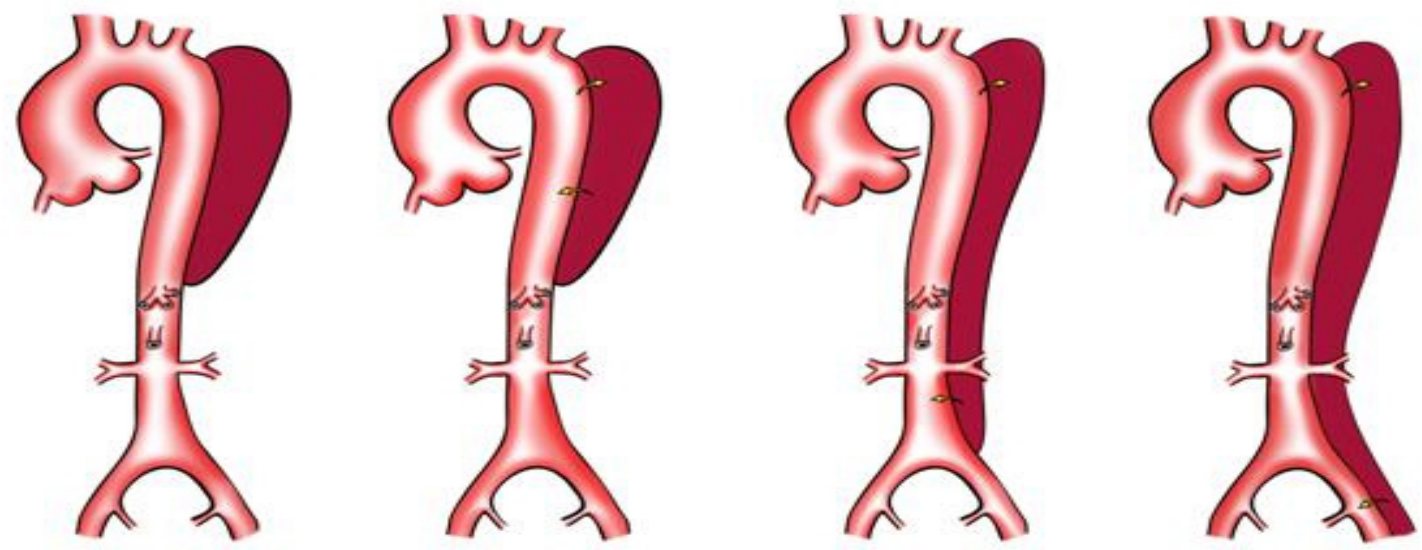
Las disecciones no complicadas de la aorta descendente (tipo B) tienen una mortalidad estimada acumulada de 10 $\%$ a los 30 días, y podrían eventualmente ser manejadas médicamente o a través de cirugía endovascular. Los hematomas intramurales de la aorta ascendente y descendente tienen el mismo pronóstico que las disecciones tipo A y B correspondientemente

Los textos de medicina describen el cuadro clínico de la disección típicamente con dolor torácico o en la espalda, severo, desgarrante o sordo y en algunos casos irradiado. Sin embargo, y contrariamente a lo enseñado en las escuelas de medicina, el clásico dolor tipo desgarrante y/o migratorio no ha sido descrito con frecuencia en el Registro Internacional de Disecciones Agudas Aórticas (International Registry of Acute Aortic Dissection - IRAD). Por el contrario, el dolor severo tipo punzada ha sido el más frecuentemente descrito por los pacientes. Adicionalmente, se reconoce alrededor de $4,5 \%$ de los pacientes sin dolor al momento de la presentación.

El dolor torácico ha sido significativamente más frecuente en las disecciones tipo A (79\% versus 63\% del tipo B); en contraste con el dolor de espalda para ambos $(64 \%$ versus $47 \%$ ) y el dolor abdominal (43\% versus $22 \%$ ), significativamente más frecuentes en la disección tipo B. ${ }^{12}$ La hipertensión arterial es el factor de riesgo más asociado a la disección de aorta, aunque se encuentra presente muy poco en el momento de la presentación clínica; en particular con los pacientes con disección aórtica proximal $(36 \%$ versus $70 \%$ para la disección tipo B).

El síncope es también un síntoma asociado a la disección aórtica, indicando a menudo el desarrollo de complicaciones peligrosas, tales como taponamiento, obstrucción de vasos sanguíneos cerebrales, o activación de baroreceptores. El síncope se ha reportado en 13\% de los pacientes del IRAD. ${ }^{13}$ Estos pacientes tuvieron mayor probabilidad de morir en el hospital (34\% versus $23 \%$ sin síncope) y tuvieron mayor probabilidad de desarrollar taponamiento cardiaco, ictus cerebral, déficit neurológico y una disección proximal.

La diferencia en la amplitud de los pulsos (o déficit de los pulsos) también ha sido estudiado en el IRAD. Esta diferencia de pulso ha sido descrita en $19 \%$ a $30 \%$ de los pacientes con disección tipo A, comparado con $9 \%$ a $21 \%$ de los pacientes con disección tipo B. ${ }^{14-16}$ Estos pacientes tuvieron una alta tasa de complicaciones y mortalidad hospitalaria comparativamente contra los que no tuvieron diferencia de pulso.

En relación a las diferencias clínicas entre los pacientes ancianos, jóvenes y mujeres, de un total de 550 pacientes con disección tipo A registrados en el IRAD, 32\% tuvieron 70 años de edad. ${ }^{17}$ Los signos y síntomas típicos de la disección (dolor torácico o en la espalda de inicio súbito, soplo de regurgitación aórtica o pulso deficitario) fueron menos comunes en la población geronte. La mortalidad hospitalaria fue mucho mayor en pacientes ancianos (43\% versus $28 \%$ ), y los análisis de regresión logística identificaron la edad de 70 años como un factor predictor independiente para muerte hospitalaria en las disecciones tipo A. Los pacientes adultos jóvenes menores de 40 años correspondieron al $7 \%$ de la cohorte pero no presentaron diferencias significativas con respecto a la presentación clínica frente al grupo de edad igual o mayo de 40 años. ${ }^{18}$ Las mujeres constituyeron el $32 \%$ de los registros del IRAD, y la alteración del sensorio fue más común en este subgrupo, mientras que el pulso deficitario fue menos frecuente. ${ }^{19}$

Los pacientes que se presentaron con dolor abdominal tuvieron una mayor mortalidad que aquellos que se presentaron con signos más típicos $(28 \%$ versus $10.2 \%)$ y una mayor tendencia para la demora en el diagnóstico. ${ }^{20}$ Esto enfatiza la posibilidad de tener sintomatología atípica y presentar una disección que simula otras condiciones tales como el ictus, infarto de miocardio, embolia vascular u otra patología abdominal. Por ende, para el diagnóstico de esta enfermedad se requiere de un alto índice de sospecha en los pacientes con factores de riesgo.

El manejo inicial del síndrome aórtico agudo está enfocado en el control de la presión arterial para reducir la tensión en la pared vascular. Se requiere de la evaluación de un equipo multidisciplinario para decidir entre ofrecer tratamiento endovascular y quirúrgico convencional; o continuar con manejo médico. ${ }^{21}$

Los betabloqueadores son los agentes más adecuados y deben ser titulados para reducir la frecuencia cardíaca y la presión arterial al nivel más bajo tolerable que asegure la perfusión cerebral, coronaria y renal. Para la mayoría de los pacientes, es posible lograrlo manteniendo una presión arterial sistólica entre 100 y 120 mm Hg con una frecuencia cardíaca de 60 o menos. En pacientes con potencial intolerancia a los betabloqueadores (falla cardiaca, bradicardia, asma), el esmolol es una opción razonable debido a su corta vida media que permite probar la reacción del paciente a los betabloqueadores. El rol del uso de calcioantagonistas es menos claro; sin embargo, en pacientes intolerantes a los betabloqueadores o con contraindicación absoluta, el verapamilo y diltiazem pueden ser útiles para reducir la presión arterial sin producir taquicardia refleja. Si el uso de los betabloqueadores solos (metoprolol, esmolol, labetalol) no es suficiente para controlar la presión arterial, se debe utilizar vasodilatadores, pero nunca como monoterapia sino de manera conjunta con los betabloqueadores. El nitroprusiato es el vasodilatador de elección. El dolor también debe ser controlado porque contribuye a la taquicardia e hipertensión, siendo la morfina el medicamento de elección.

En los pacientes con presión arterial normal o baja al momento de la presentación clínica, se debe considerar la posibilidad de depleción de volumen debida a hemorragia en un falso lumen, hemopericardio, hemomediastino, o hemotórax. Estos pacientes podrían requerir intubación precoz antes del estudio tomográfico. Si hubiera taponamiento pericárdico, la pericardiocentesis como una medida terapéutica antes de la cirugía puede ser dañina debido a que disminuye la presion intrapericárdica y por tanto un sangrado pericárdico recurrente y muerte súbita. ${ }^{22}$ 
Recomendaciones para el manejo médico de los sindromes aórtico agudos ${ }^{23}$

\begin{tabular}{|l|c|}
\hline Intervención & Clase de recomendación \\
\hline ECG para documentar isquemia & I \\
\hline Monitoreo de frecuencia cardiaca y presión arterial & I \\
\hline Control del dolor (morfina) & I \\
\hline Reducción de la presión sistólica con betabloqueadores (metoprolol, esmolol o labetalol intravenosos) & I \\
\hline $\begin{array}{l}\text { En pacientes con hipertensión severa a pesar del uso de betabloqueadores, utilizar vasodilatadores } \\
\text { (nitroprusiato para lograr PAS entre I00 a I } 20 \mathrm{~mm} \mathrm{Hg} \text { ) }\end{array}$ & I \\
\hline En pacientes con enfermedad pulmonar obstructiva, controlar la presión arterial con calcioantagonistas & II \\
\hline $\begin{array}{l}\text { Realizar estudio emergente de imágenes en pacientes con signos electrocardiográficos de isquemia } \\
\text { miocárdica antes de realizar trombolisis si se ha sospechado patología aórtica }\end{array}$ & II \\
\hline Radiografía de tórax & III \\
\hline
\end{tabular}

Tratamiento quirúrgico para disecciones agudas tipo $\mathrm{A}$ de la aorta

\begin{tabular}{|l|c|}
\hline Intervención & Clase de recomendación \\
\hline Cirugía emergente para prevenir taponamiento/ruptura aórtica & I \\
\hline $\begin{array}{l}\text { Cirugía para preservar válvulas, injerto tubular si la raíz de la aorta es normal y no hay cambios patológicos } \\
\text { en las cúspides valvulares }\end{array}$ & I \\
\hline $\begin{array}{l}\text { Reemplazo de la aorta y válvula aórtica (injerto compuesto) si se presentan cambios proximales } \\
\text { patológicos tipo estático en la válvula o pared aórtica. }\end{array}$ & I \\
\hline Cirugías que respetan la válvula con remodelamiento de la raíz aórtica para válvulas anormales & Ila \\
\hline Preservación de la válvula y remodelamiento de la raíz aórtica en pacientes con Marfan & Ila \\
\hline
\end{tabular}

La disección aórtica aguda tipo A (incluyendo disección aguda, hematoma intramural, úlcera penetrante aórtica) debe ser tratada como una emergencia quirúrgica debido a las complicaciones potencialmente mortales tales como la ruptura aórtica, taponamiento cardíaco y la alta mortalidad asociada a esta condición. La cirugía busca disminuir la regurgitación aórtica y restablecer la perfusión coronaria y del resto de ramas arteriales.

Las disecciones tipo B no complicadas pueden ser manejadas medicamente con analgésicos y antihipertensivos; y es seguro tratarlos acompañados de un seguimiento clínico estrecho que permita identificar complicaciones isquémicas, progresión de la disección o agrandamiento aneurismático. En un grupo de 384 paciente con disección tipo B, el 73\% fue tratado medicamente con una mortalidad intrahospitalaria del $10 \%$. La tasa de supervivencia observada fue de 60 a $80 \%$ en cinco años. ${ }^{24}$

Las disecciones tipo B complicadas se caracterizan por síndrome de mala perfusión distal o rápida progresión. Las indicaciones para realizar una intervención quirúrgica son similares al tipo A: prevención de complicaciones potencialmente mortales tales como las isquemias de las extremidades u órganos, expansión aneurismática y riesgo de ruptura, hemorragia retroperitoneal, dolor intratable, hipertensión no controlada. La tasa de mortalidad para las cirugías convencionales (procedimiento para el reemplazo con injertos vasculares, fenestración o bypass) es de 30 a $35 \%$ e incluso mayor si hay mala perfusión visceral. ${ }^{25.26}$
El injerto aórtico endovascular puede ser beneficioso en este grupo de pacientes y ha demostrado mejora en las tasas de mortalidad (16\%). Las metas del tratamiento endovascular incluyen la reconstrucción del segmento que contiene la entrada al desgarro, inducción de trombosis en el lumen falso y restablecimiento del flujo en el lumen real y sus $\operatorname{ramas}^{27}$ En una serie de pacientes, la trombosis del falso lumen se logró en 85 a 100\% de los pacientes tratados endovascularmente.

Los endoinjertos han sido utilizados en pacientes con disecciones tipo A retrógradas con desgarros en la íntima de la aorta descendente, induciendo trombosis en el falso lumen. ${ }^{28}$

El tratamiento quirúrgico sigue siendo la opción en los pacientes en los que los endoinjertos han fallado o no son candidatos a estas técnicas menos invasivas.

Independientemente del manejo quirúrgico, endovascular o médico, el riesgo de una nueva disección nunca es totalmente eliminado. Luego de la fase aguda, la sobrevida a mediano o largo plazo depende no solo de la enfermedad aórtica subyacente, sino también de las comorbilidades. Por tanto, el monitoreo cercano y regular, es necesario para evaluar la progresión y complicaciones.

En conclusión, en ambos casos, la presentación clínica de los síndromes aórticos agudos (hematoma intramural aórtico del caso 1 y disección aórtica del caso 2) fue atípica, correspondiendo a lo descrito en el IRAD. Por esta razón, es altamente recomendable siempre mantener un 
Recomendaciones para el manejo endovascular

\begin{tabular}{|l|l|}
\hline Intervención & Clase de recomendación \\
\hline Colocación de stent en el origen de la rama obstruída para obstrucciones estáticas de la rama arterial & Ila \\
\hline $\begin{array}{l}\text { Fenestración de la membrana disecante con balón más colocación de stent en el lumen aórtico real para } \\
\text { obstrucciones dinámicas }\end{array}$ & Ila \\
\hline Colocación de stent para mantener la fenestración abierta & Ila \\
\hline Fenestración para proveer vía de reentrada para el final del falso lumen & Ila \\
\hline Colocación de stent en el lumen real para sellar la entrada & Illb \\
\hline Colocación de stent para agrandar el lumen real comprimido & Ila \\
\hline
\end{tabular}

alto nivel de alerta clínica sobre los pacientes en las salas de emergencia, incluso en aquellos en los que se presume alguna otra patología como diagnóstico principal.

Se recomienda utilizar protocolos de actuación orientados a ofrecer una respuesta rápida frente a estas patologías, así como para acelerar el proceso de diagnóstico y manejo quirúrgico emergente si el caso lo requiriera.

Ante la sospecha y/o evidencia de un síndrome aórtico agudo, se debe desplegar inmediatamente todos los recursos disponibles para controlar la presión arterial (PAS 100-120 $\mathrm{mm} \mathrm{Hg}$ ) y frecuencia cardíaca (menor o igual a 60) como primeras medidas. Los betabloqueadores parenterales (metoprolol, labetalol, esmolol) solos y/o asociados a vasodilatadores (nitroprusiato) son las primeras líneas farmacológicas a utilizar.

En todos estos casos, la interconsulta de emergencia a cirugía de tórax y vascular es obligatoria, asumiendo siempre el peor escenario a favor del paciente.

De acuerdo a la condición clínica del paciente y la capacidad instalada del establecimiento de salud, se deben elegir los estudios de imágenes más adecuados, pudiendo utilizarse rayos $\mathrm{X}$, ultrasonografía, tomografía axial, angioTEM, resonancia magnética nuclear.

\section{REFERENCIAS BIBLIOGRÁFICAS}

I. Nienaber CA, Powell JT. Management of acute aortic syndromes. Eur Heart J. 20I2; 33:26-35.

2. Salvolini L, Renda P, Fiore D, Scaglione M, Piccoli G, Giovagnoni A. Acute aortic syndromes: role of multi-detector row CT. Eur J Radiol. 2008; 65:350-358.

3. Nienaber CA, Fattori R, Mehta RH, et al. Gender-related differences in acute aortic dissection. Circulation. 2004; 109:3014-302 I

4. Hagan PG, Nienaber CA, Isselbacher EM, et al. The International Registry of Acute Aortic Dissection (IRAD): new insights into an old disease. JAMA. 2000; 283:897-903

5. Meszaros I, Morocz J, Szlavi J, Schmidt J, Tornoci L, Nagy L, Szep L. Epidemiology and clinicopathology of aortic dissection. Chest. 2000; I 17: I27-1278.

6. Roberts CS, Roberts WC. Aortic dissection with the entrance tear in the descending thoracic aorta: analysis of 40 necropsy patients. Ann Surg. 1991;213:356-368.

7. Masuda Y, Takanashi K, Takasu J, Watanabe S. Natural history and prognosis of medical treatment for the patients with aortic dissections [in Japanese]. Nippon Geka Gakkai Zasshi. 1996;97:890893.

8. Bogaert J, Meyns B, Rademakers FE, Bosmans $H$, Verschakelen
J, Flameng W, Marchal G, Baert AL. Follow-up of aortic dissection: contribution of MR angiography for evaluation of the abdominal aorta and its branches. Eur Radiol. 1997;7:695-702.

9. Hagan PG, Nienaber CA, Isselbacher EM, et al. The International Registry of Acute Aortic Dissection (IRAD): new insights into an old disease. JAMA. 2000;283:897-903.

10. Mehta RH, O'Gara PT, Bossone E, et al.Acute typeA aortic dissection in the elderly: clinical characteristics, management, and outcomes in the current era. J Am Coll Cardiol. 2002;40:685-692.

I I. Mehta RH, Suzuki T, Hagan PG, et al. Predicting death in patients with acute type A aortic dissection. Circulation. 2002; 105:200-206.

12. Hagan PG, Nienaber CA, Isselbacher EM, Bruckman D, Karavite DJ, Russman PL, Evangelista A, Fattori R, Suzuki T, Oh JK, Moore AG, Malouf JF, Pape LA, Gaca C, Sechtem U, Lenferink S, Deutsch HJ, Diedrichs H, Marcos y Robles J, Llovet A, Gilon D, Das SK,Armstrong WF, Deeb GM, Eagle KA. The International Registry of Acute Aortic Dissection (IRAD): new insights into an old disease.JAMA. 2000; 283: 897-903.

13. Nallamothu BK, Mehta RH, Saint S, Llovet A, Bossone E, Cooper JV, Sechtem U, Isselbacher EM, Nienaber CA, Eagle KA, Evangelista A. Syncope in acute aortic dissection: diagnostic, prognostic, and clinical implications. Am J Med. 2002; I I 3:468-47I.

14. Hagan PG, Nienaber CA, Isselbacher EM, Bruckman D, Karavite DJ, Russman PL, Evangelista A, Fattori R, Suzuki T, Oh JK, Moore AG, Malouf JF, Pape LA, Gaca C, Sechtem U, Lenferink S, Deutsch HJ, Diedrichs H, Marcos y Robles J, Llovet A, Gilon D, Das SK,Armstrong WF, Deeb GM, Eagle KA. The International Registry of Acute Aortic Dissection (IRAD): new insights into an old disease. JAMA. 2000;283:897-903.

I5. Suzuki T, Mehta RH, Ince H, Nagai R, Sakomura Y,Weber F, Sumiyoshi T, Bossone E, Trimarchi S, Cooper JV, Smith DE, Isselbacher EM, Eagle KA, Nienaber CA. Clinical profiles and outcomes of acute type $B$ aortic dissection in the current era: lessons from the International Registry of Aortic Dissection (IRAD). Circulation. 2003; I08(suppl II):II-3I2-II-3I 7 .

16 Bossone E, RampoldiV, Nienaber CA,Trimarchi S, Ballotta A, Cooper JV, Smith DE, Eagle KA, Mehta RH. Usefulness of pulse deficit to predict in-hospital complications and mortality in patients with acute type A aortic dissection. Am J Cardiol. 2002;89:85I- 855.

17. Mehta RH, O'Gara PT, Bossone E, Nienaber CA, Myrmel T, Cooper JV, Smith DE,ArmstrongWF, Isselbacher EM, Pape LA, Eagle KA, Gilon D.Acute typeA aortic dissection in the elderly:clinical characteristics, management, and outcomes in the current era. J Am Coll Cardiol. 2002; 40:685-692.

18. Januzzi JL, Isselbacher EM, Fattori R, Cooper JV, Smith DE, Fang J, Eagle KA, Mehta RH, Nienaber CA, Pape LA. Characterizing the young patient with aortic dissection: results from the International Registry of Aortic Dissection (IRAD). J Am Coll Cardiol. 2004;43:665669.

19. Nienaber CA, Fattori R, Mehta RH, Richartz BM, Evangelista A Petzsch M, Cooper JV, Januzzi JL, Ince H, Sechtem U, Bossone E, Fang J, Smith DE, Isselbacher EM, Pape LA, Eagle KA. Gender-related differences in acute aortic dissection. Circulation. 2004;109:3014- 
3021.

20. Upchurch GR, Jr., Nienaber C, Fattori R, Evangelista A, Oh J, Cooper JV, Isselbacher E, Suzuki T, Eagle KA. Acute aortic dissection presenting with primarily abdominal pain: a rare manifestation of a deadly disease. Ann Vasc Surg. 2005; 19:367-373.

21. Clough RE, Nienaber CA, Management of acute aortic syndrome. Nature Reviews Cardiology. 2015; 12:103-1 I4.

22. Isselbacher EM, Cigarroa JE, Eagle KA. Cardiac tamponade complicating proximal aortic dissection: is pericardiocentesis harmful? Circulation. 1994;90:2375-2378

23. Tsai TT, Nienaber CA, Eagle KA. Contemporary Reviews in Cardiovascular Medicine. Acute Aortic Syndromes. Circulation. 2005; I I2:3802-38I3

24. Hagan PG, Nienaber CA, Isselbacher EM, et al. The International Registry of Acute Aortic Dissection (IRAD): new insights into an old disease. JAMA. 2000;283:897-903.
25. Heinemann MK, Buehner B, Schaefers HJ, Jurmann MJ, Laas J, Borst HG. Malperfusion of the thoracoabdominal vasculature in aortic dissection.J Card Surg. 1994;9:748-755.

26. Borst HG, Laas J, Heinemann M. Type A aortic dissection: diagnosis and management of malperfusion phenomena. Semin Thorac Cardiovasc Surg. 1991;3:238-241.

27. Ince $\mathrm{H}$, Nienaber CA.The concept of interventional therapy in acute aortic syndrome.J Card Surg. 2002; 17:135-142.

28. Kato N, Shimono T, Hirano T, Ishida M, Yada I,Takeda K. Transluminal placement of endovascular stent-grafts for the treatment of type $A$ aortic dissection with an entry tear in the descending aorta. J Vasc Surg. 2001;34:1023-1028.

\section{CORRESPONDENCIA}

Oscar Guzmán Del Giudice

dr.oscar.guzman@gmail.com

Fecha de recepción: 07-II-2020.

Fecha de aceptación: 10-0I-202I. 